\title{
The Coherence of Evolutionary Theory with Its Neighboring Theories
}

\author{
Forthcoming in Acta Biotheoretica
}

\author{
Seungbae Park \\ Ulsan National Institute of Science and Technology \\ The Republic of Korea
}

\begin{abstract}
Evolutionary theory coheres with its neighboring theories, such as the theory of plate tectonics, molecular biology, electromagnetic theory, and the germ theory of disease. These neighboring theories were previously unconceived, but they were later conceived, and then they cohered with evolutionary theory. Since evolutionary theory has been strengthened by its several neighboring theories that were previously unconceived, it will be strengthened by infinitely many hitherto unconceived neighboring theories. This argument for evolutionary theory echoes the problem of unconceived alternatives. Ironically, however, the former recommends that we take the realist attitude toward evolutionary theory, and the latter recommends that we take the antirealist attitude toward it.
\end{abstract}

\section{Keywords}

Coherence, Evolutionary Theory, Joint Explanation, Unconceived Neighboring Theories

\section{Introduction}

Evolutionary theory receives support from its neighboring theories, such as the theory of plate tectonics, molecular biology, electromagnetic theory, and the germ theory of disease. These neighboring theories were previously unconceived, but they were later conceived, and then they supported evolutionary theory. From this observation, I construct what I call the argument from neighboring theories, according to which because evolutionary theory has been supported by its several neighboring theories that were previously unconceived, it will be supported by infinitely many hitherto unconceived neighboring theories.

In Section 2, I expound upon P. Kyle Stanford's (2006) problem of unconceived alternatives (PUA), which asserts that there are infinitely many hitherto unconceived alternatives to current theories. In Section 3, I specify how evolutionary theory receives support from its neighboring theories mentioned above. In Section 4, I spell out the argument from neighboring theories. In Section 5, I reply to eight objections most of which are raised by the reviewers of this journal. It will become clear that the argument from neighboring theories is stronger than the PUA, and that it is different from Hilary Putnam's (1975) nomiracles argument, the most famous argument for scientific realism.

This paper should be of interest to those who want to know how current theories differ from obsolete theories, whether the former will follow the unfortunate fate of the latter, and whether there are arguments other than the no-miracles argument that are intended to establish scientific realism.

\section{The PUA}

The argument from neighboring theories parallels Stanford's (2006) PUA. So I explicate the PUA in this section.

The PUA holds that earlier scientists could not entertain current theories that displaced past theories, but later scientists entertained current theories, so current scientists cannot ideate future alternatives that will displace current theories, but future scientists will ideate 
future alternatives. For example, caloric theorists could not conceive of the kinetic theory, but later scientists conceived of the kinetic theory, so kinetic theorists cannot conceive of a future theory that will displace the kinetic theory, but future scientists will conceive of the future theory. On this account, scientific theories are fated to be rejected. In order to support the PUA, Stanford offers the following list of theory transitions:

\section{$\underline{\text { Stanford's List }}$}

from elemental to early corpuscularian chemistry to Stahl's phlogiston theory to Lavoisier's oxygen chemistry to Daltonian atomic and contemporary chemistry

from various versions of preformationism to epigenetic theories of embryology

from the caloric theory of heat to later and ultimately contemporary thermodynamic theories

from effluvial theories of electricity and magnetism to theories of the electromagnetic ether and contemporary electromagnetism

from humoral imbalance to miasmatic to contagion and ultimately germ theories of disease

from eighteenth century corpuscular theories of light to nineteenth century wave theories to the contemporary quantum mechanical conception

from Darwin's pangenesis theory of inheritance to Weismann's germ-plasm theory to Mendelian and then contemporary molecular genetics

from Cuvier's theory of functionally integrated and necessarily static biological species and from Lamarck's autogenesis to Darwin's evolutionary theory (Stanford, 2006: 19-20)

On the basis of this list, Stanford concludes that the possibility space of successive alternatives "appears to be indeterminate and unbounded" (2006: 133). Each item on the list is composed of, at most, several theories. For example, the fifth item on the list is comprised of the three theories of disease. These three theories, according to Stanford, provide an inductive rationale for the conclusion that there are an infinite number of theories of disease. Current scientists cannot conceive of them, but they exist. The fact that current scientists cannot entertain them only shows that they are cognitively analogous to earlier scientists "whose cognitive constitutions are not well suited to the task of exhausting the kinds of spaces of serious candidate theoretical explanations from which our scientific theories are drawn" (Stanford, 2006: 45). In short, according to Stanford, even a series of several successive theories in a domain amounts to an inductive rationale for the conclusion that there are infinitely many successive theories in that domain.

\section{Evolutionary Theory and Its Neighboring Theories}

Suppose that $T_{1}$ and $T_{2}$ are theories in neighboring fields of science, and that each explains its own phenomena. If $\mathrm{T}_{1}$ and $\mathrm{T}_{2}$ are conjoined, they may explain or predict new phenomena, i.e., they may yield new observational consequences that agree with the world (Psillos, 1999: 205). This section aims to show that evolutionary theory, in conjunction with its several neighboring theories, explains or predicts diverse new phenomena.

Evolutionary theory, in conjunction with the theory of plate tectonics, predicted that there are fossils of marsupials in Antarctica. According to evolutionary theory, marsupials flourished in South America hundreds of millions of years ago. According to the theory of plate tectonics, Australia, South America, and Antarctica were once connected with each 
other and then gradually drifted apart. On the basis of these assumptions, scientists (Woodburne and Zinsmeister, 1982) retrodicted that marsupials migrated from South America to Australia via Antarctica and predicted that there are fossils of marsupials in Antarctica. This prediction, which was confirmed, was made possible by the cooperation of evolutionary theory with the theory of plate tectonics.

Evolutionary theory, together with molecular biology, explains why some people are affected by Huntington's disease, a genetic disease that disrupts nerve cells and ultimately leads to death. The Huntington's Disease Collaborative Research Group (1993) identified the gene responsible for the disease. It is mysterious why this gene still exists. Given that it causes a deadly disease, natural selection should have weeded it out of our gene pool. According to evolutionary theory and molecular biology, the gene has escaped natural selection by not affecting people until after they have reproduced, thus sneaking into successive generations and thereby causing Huntington's disease in some people today. Note that concepts from both evolutionary theory and molecular biology are employed to explain why Huntington's disease afflicts some people today.

Evolutionary theory and electromagnetic theory jointly explain why different people have different skin pigmentations. According to these two theories, when hominins, our distant ancestors, lived in Africa, natural selection favored darkly pigmented individuals. Ultraviolet rays destroyed folate in the cutaneous blood vessels of lightly pigmented individuals but not darkly pigmented individuals. A high level of folate during pregnancy was crucial for having healthy babies. Some hominins began to migrate to other continents about 1.9 million years ago. Near the poles, natural selection favored lightly pigmented individuals. Ultraviolet rays generated vitamin D in the skins of lightly pigmented individuals but not in the skins of darkly pigmented individuals. Vitamin D was crucial for maintaining health. In between the equator and the poles, natural selection favored those who were capable of tanning during the season when ultraviolet light was intense (Jablonski and Chaplin, 2010).

Together, evolutionary theory, the germ theory, and molecular biology explain why some bacteria become resistant to antibiotics. According to these theories, some bacteria evolve much faster than other organisms due to their short lifespans, large populations, and horizontal gene transfer, which is the gene transfer between organisms of the same generation (Soucy, Huang \& Gogarten, 2015). It contrasts with vertical gene transfer, which is the gene transfer from one generation to the next generation. Horizontal gene transfer is followed by genetic mutations, which, in turn, facilitate the advent of new bacteria resistant to old antibiotics. Note that notions from evolutionary biology, the germ theory, and molecular biology are used to explain why new bacteria survive old antibiotics. Such a rich explanation might better yield a clue as to how to control bacteria.

So far, I have shown that evolutionary theory explains diverse new phenomena in conjunction with its neighboring theories. Those neighboring theories are not isolated from one another. In what follows, I show that they themselves also jointly explain new phenomena. Let me begin with electromagnetic theory and the theory of plate tectonics.

These two theories jointly explain the symmetrical magnetic stripes on ocean floors (Trefil and Hazen, 1998: 403-405). According to electromagnetic theory, Earth's magnetic field flips back and forth every few million years. According to the theory of plate tectonics, an ocean basin spreads due to the convection of the mantle. The magnetic stripes are explained as follows. The magma that erupted at a mid-ocean ridge contained magnetic minerals, which aligned themselves parallel to Earth's magnetic field while the lava was hot. Once the lava hardened, the minerals became immobile. Earth's magnetic field flipped around, as magma continuously erupted at the mid-ocean ridge. Magnetic minerals in the new lava aligned themselves in the opposite directions, forming new magnetic stripes as the lava 
hardened. Many symmetrical magnetic stripes were thus created as a result of the repeated magnetic reversals and the spreading of the sea floor.

The theory of plate tectonics and molecular biology jointly explain the distribution of certain organisms. For example, freshwater gastropods are found in Southeast Asia and southern India. According to the theory of plate tectonics, Peninsular India was part of Gondwana about 200 million years ago. It drifted away from Gondwana and then collided with the Eurasian plate about 30-40 million years ago. An exchange of biota between Peninsular India and Asia resulted from the collision. A molecular study suggests that the gastropods of Southeast Asia migrated to southern India (Datta-Roy and Karanth, 2009: 688). To take another example, arowanas are freshwater fish that are intolerant of salty water. They, however, inhabit Southeast Asia and Australasia. How could they live in these different continents separated by salt water? The paleogeographical information and molecular data suggest that their common ancestors lived in Gondwana, and that the ancestors of Asian arowanas were transported northward by the Indian subcontinent, which had been part of Gondwana but moved to Asia (Kumazawa and Nishida, 2000).

Molecular biology and electromagnetic theory jointly explain why our skin develops cancer when over-exposed to sunshine (Trefil and Hazen, 1998: 155-156). The wavelengths of ultraviolet light are smaller than those of infrared and visible light. So ultraviolet light carries more energy than infrared and visible light. Skin cancer occurs when ultraviolet light, which is more powerful than infrared and visible light, destroys DNA molecules in our skin. Note that concepts from molecular biology and electromagnetic theory are jointly invoked to explain why skin cancer occurs.

Electromagnetic theory, the germ theory, and molecular biology jointly explain how daily objects, such as kitchen utensils, computer keyboards, and mobile phones, are sanitized. There are invisible germs on the surfaces of daily objects. They can be killed by ultraviolet light. Ultraviolet light can penetrate their cell membranes and damage their DNA. Such a method to destroy microorganisms is called ultraviolet germicidal irradiation (Kowalski, 2009). It has been an accepted method of disinfection since the mid-twentieth century. If a kitchen utensil is sanitized using this method, that can be explained with the use of electromagnetic theory, the germ theory, and molecular biology.

\section{The Argument from Neighboring Theories}

In this section, I unfold the philosophical implications of the fact that evolutionary theory explains or predicts diverse new phenomena in cooperation with its neighboring theories.

Michael Friedman observes that atomic theory and the hypothesis of molecular constitution jointly "explain chemical bonding, thermal and electrical conduction, nuclear energy, genetic inheritance, and literally hundreds of other phenomena" (1981: 7). He emphasizes that atomic theory and the hypothesis have become more likely to be true as a result of jointly explaining new phenomena. His insight can be captured by the concept of coherence (Park, 2011a: 23-24). To say that $\mathrm{T}_{1}$ coheres with $\mathrm{T}_{2}$ means that they support each other to some extent.

Evolutionary theory and its neighboring theories cohere with each other as a result of jointly explaining new phenomena. Evolutionary theory raises, to some extent, the probability that the theory of plate tectonics is true, and vice versa. Though evolutionary theory might not have enough epistemic force to show that the theory of plate tectonics is likely to be true, and vice versa, they both become more likely to be true as a result of cohering with each other. They are more than merely consistent with each other. Consistency means only that they do not contradict each other. The idea that scientific theories can cohere with one another goes well with Carl Hempel's observation that a scientific theory can 
receive support from other scientific theories (Hempel, 1966: 38-39).

$\mathrm{T}_{1}$ and $\mathrm{T}_{2}$ can directly and/or indirectly cohere with each other (Park, 2011a: 25). The theory of evolution and the theory of plate tectonics directly cohere since they jointly explain the fossils of marsupials in Antarctica. The theory of plate tectonics and electromagnetic theory directly cohere since they jointly explain magnetic stripes on ocean floors. It follows that evolutionary theory indirectly coheres with electromagnetic theory, i.e., that they cohere with each other via the intermediate theory, viz., the theory of plate tectonics. Evolutionary theory and electromagnetic theory, however, also directly cohere with each other since they jointly explain different skin pigmentations. Thus, they cohere with each other not only directly but also indirectly.

In the previous section, we observed that evolutionary theory directly coheres with its several neighboring theories. The neighboring theories constitute the following list:

\section{List of Neighboring Theories}

- the theory of plate tectonics

- molecular biology

- electromagnetic theory

- the germ theory

These theories were all previously unconceived, but they were later conceived, and then they cohered with evolutionary theory. So they might be retrospectively called unconceived neighboring theories. The concept of an unconceived neighboring theory differs from that of an unconceived alternative developed by Stanford (2006). By 'an unconceived alternative,' Stanford means a rival theory that would supplant an accepted theory. For example, the oxygen theory was an unconceived alternative to the phlogiston theory. By 'a neighboring theory,' however, I do not mean a rival or an alternative to an accepted theory. I rather mean a theory in a neighboring field of science.

Let me flesh out the argument from neighboring theories mentioned earlier. The fact that evolutionary theory coheres with its several neighboring theories, which had been previously unconceived, makes it likely that there are more neighboring theories, presently unconceived, that will cohere with evolutionary theory. The more that such theories are produced, the greater the inductive rationale will become for the conclusion that there will be even more such theories. It probably follows that there are infinitely many such theories. It is not merely possible but likely that they exist. In short, since evolutionary theory coheres with its several neighboring theories, it will cohere with infinitely many neighboring theories.

The argument from neighboring theories is intended to justify evolutionary theory but not other scientific theories. So if scientific antirealists want to refute the argument from neighboring theories, they should provide neighboring theories that were previously unconceived, but that were later conceived and then clashed with evolutionary theory. If the number of such theories is greater than that of theories that were unconceived, but that were later conceived, and then cohered with evolutionary theory, the argument from neighboring theories would be defeated. ${ }^{1}$

We have good reason for thinking that we cannot find neighboring theories that clashed

\footnotetext{
${ }^{1}$ What matters is not only the number of neighboring theories but also the degrees to which they are supported. The probability of evolutionary theory goes up, although it clashes with two moderately supported neighboring theories, if it coheres with one extremely well-supported neighboring theory. I thank the first referee for making this point.
} 
with evolutionary theory before the twentieth century. Up until the end of the nineteenth century, high walls separated the different fields of science (Park, 2011b: 80-89). For example, biologists and chemists did not communicate with one another until the end of the nineteenth century when Louis Pasteur (1822-1895) persuaded medical doctors that some diseases could be chemically understood. To take another example, geologists and physicists did not communicate with one another until the end of the nineteenth century, when geologists began to use the radioactive method to determine the age of various materials and to set up hypotheses about distant past events. So it is unlikely that evolutionary theory has ever clashed with a neighboring theory.

One might object that evolutionary theory conflicts with the kinetic theory. Evolutionary theory claims that organisms have evolved from simple to complex forms, which implies that the entropy of Earth has been decreasing. The second law of thermodynamics, however, claims that entropy tends to increase. Thus, evolutionary theory would seem to clash with the kinetic theory.

This objection, however, rests upon a misunderstanding of the second law of thermodynamics. The second law of thermodynamics does not assert that the entropy of just any system tends to increase. It rather asserts that the entropy of a closed system tends to increase. Consequently, it is compatible with the fact that the entropy of an open system decreases. Earth is an open system in that it receives energy from the Sun. Thus, on close examination, evolutionary theory is consistent with the kinetic theory.

Scientific antirealists might argue that we cannot conceive of infinitely many neighboring theories that will cohere with evolutionary theory, so they do not exist. An obvious reply to this objection, however, is that we have the aforementioned inductive rationale for the view that they exist. Moreover, the fact that we cannot conceive of them shows not that they do not exist, but rather that we are not more intelligent than earlier scientists who could not conceive of infinitely many neighboring theories that were fated to cohere with evolutionary theory.

The argument from neighboring theories mirrors the PUA. Just as Stanford contends that the possibility space of alternatives is inhabited by infinitely many hitherto unconceived theories of disease on the grounds that there have been three theories of disease, so I contend that the possibility space of neighboring theories is inhabited by infinitely many hitherto unconceived neighboring theories that will cohere with evolutionary theory on the grounds that several previously unconceived neighboring theories now cohere with evolutionary theory. Just as Stanford claims that the inability of present scientists to think up infinitely many alternatives only indicates that they are cognitively similar to earlier scientists who could not think up infinitely many alternatives, so I claim that the inability of present scientists to think up infinitely many theories that will cohere with evolutionary theory only indicates that they are cognitively similar to earlier scientists who could not think up infinitely many neighboring theories that would cohere with evolutionary theory. Accordingly, the argument from neighboring theories and the PUA stand or fall together.

The argument from neighboring theories also echoes the argument for special relativity (Park, 2018a: 59). It holds that special relativity has been strengthened by several methods that were previously unconceived, such as fast-moving jets, the global positioning system, atomic clocks, and particle accelerators. It probably follows that it will be strengthened by infinitely many hitherto unconceived methods. We are warranted in believing now that it is true, even if its present observational evidence endows it with only $1 \%$ probability, given that its probability is fated to go above $99 \%$. The argument from neighboring theories has a similar effect on the probability of evolutionary theory.

The foregoing argument for special relativity is similar to the PUA in that the former 
makes an inference to infinitely many unconceived methods, and that the latter makes an inference to infinitely many theories. The argument for special relativity is also similar to K. Brad Wray's argument from unconceived methods, which holds that "some of the changes of theory in the past have been due to changes in methodology, and some of the changes of theory in the future will also likely be due to changes in methodology" (Wray, 2016: 372373). Note that the two arguments commonly make inferences to the existence of unconceived methods. In sum, the argument for special relativity utilizes ironically the two ideas that the two eminent pessimists have developed to argue against scientific realism.

The argument from neighboring theories and the no-miracles argument for scientific realism (Putnam, 1975: 73) exemplify different rules of inference. The no-miracles argument exemplifies abduction, asserting that the success of science would be a miracle, if successful theories were false, and thus, they are successful because they are true. By contrast, the argument from neighboring theories exemplifies enumerative induction, saying that since evolutionary theory is bolstered by its several neighboring theories, it will be bolstered by infinitely many neighboring theories. Scientific pessimists are not skeptics about enumerative induction - after all, if they were skeptics about enumerative induction, it would be selfdefeating for them to run the PUA against present scientific theories. Consequently, they should accept the argument from neighboring theories.

The argument from neighboring theories fits well with a current research trend in science. Scientists these days are encouraged to engage in interdisciplinary research. The idea behind interdisciplinary research seems to be that scientists in different fields can discover more about the world by sharing their research achievements with one another than by going deeper into their own fields without communicating with one another. This recent research trend in science makes it obsolete for philosophers of science to evaluate a scientific theory in isolation from its neighboring scientific theories. Stanford's PUA overlooks the fact that some present theories cohere with their neighboring theories.

The same criticism applies to Thomas Kuhn's (1962/1970) philosophy of science. Kuhn made many interesting claims about how successive theories in a field of science are related to one another. For example, he claimed that the Ptolemaic and Copernican theories were incommensurable. But he did not make any claim about how a theory is related to its neighboring theories. That is not surprising, given that he was a history-oriented philosopher of science. He used examples from past science, such as the Ptolemaic theory, the phlogiston theory, and the caloric theory, to construct his philosophy of science. Those theories were accepted and rejected before the twentieth century, and as we have seen earlier, scientists belonging to different fields did not communicate with one another until the end of the nineteenth century. So there was no chance for past theories to cohere with their neighboring theories.

By contrast, the argument from neighboring theories uses examples from present science, such as the theory of plate tectonics and evolutionary theory, and exhibits their shared property, viz., coherence. It is inadequate to say that neighboring theories are incommensurable. Biologists and geologists share observational data, although they belong to different paradigms. After all, they cooperate with one another to explain new phenomena. Moreover, they have no problem communicating with one another, given that they are engaged in interdisciplinary research, citing one another's papers. In any event, if we are informed of how neighboring theories are related to one another, we will have a better picture of science.

The argument from neighboring theories goes hand in hand with the pessimistic induction over pessimists (Park, 2017a: 612). What does the pessimistic induction over pessimists say? Imagine that pessimists in the early twentieth century predicted that their 
accepted theories, such as the germ theory, special relativity, evolutionary theory, and electromagnetic theory, would be overthrown, just as their earlier theories, such as the ether theory, the miasma theory, the caloric theory, the phlogiston theory, and the Ptolemaic theory, had been overthrown. They were wrong about their accepted theories. It follows that present and future pessimists are and will be also wrong about their accepted theories. In short, both the pessimistic induction over pessimists and the argument from neighboring theories recommend the realist attitude toward evolutionary theory.

The argument from neighboring theories undercuts not only pessimism but also selectivism. Selectivists observe that working posits of past theories were retained, but their idle posits were discarded (Worrall, 1989; Kitcher, 1993; Psillos, 1999; Chakravartty, 2008; Enfield, 2008; Godfrey-Smith, 2008; Harker, 2008; Psillos, 2009; Saatsi, 2009; Ruhmkorff, 2011: 882; Vickers, 2017; Psillos, 2018). On the basis of this observation of past theories, selectivists predict that working posits of present theories will survive scientific revolutions, though their idle posits will not. This prediction implies that present theories, including evolutionary theory, will be superseded by future theories (Park, 2017b: 98-99, 2017c: 65, 2018a: 60-61, 2018b: Section 3, 2018c: 337; Stanford, 2018: 79). The argument from neighboring theories, however, asserts that evolutionary theory will only be justified by infinitely many neighboring theories.

\section{Objections and Replies}

\subsection{Not More Probable}

Pessimists would reject Friedman's contention that two hypotheses become more probable if they jointly explain new phenomena, and hence they would also reject my contention that evolutionary theory and its neighboring theories support one another to some extent, i.e., that they cohere with one another. They would insist that the probability of evolutionary theory remains unchanged even if it jointly explains new phenomena along with its neighboring theories, e.g., even if it, in conjunction with the theory of plate tectonics, makes a true prediction about the existence of marsupial fossils in Antarctica.

My response to this objection is to point out that pessimists are not skeptics about induction. After all, they make an inductive inference from the downfall of past theories to that of present theories. Skeptics about induction would not predict anything from the downfall of past theories. It would be interesting to see what argument pessimists can come up with to show that the joint prediction of the theory of plate tectonics and evolutionary theory does not raise the probabilities of the two theories at all, but that because the caloric theory was overturned, it is likely that the kinetic theory will be overturned.

\subsection{Finitely Many Theories}

Pessimists might now contend that the existence of several successive theories in a domain justifies the conclusion that there are finitely many successive theories, but not the conclusion that there are infinitely many successive alternatives in the domain. As a result, they might modify the PUA as asserting that there are finitely many alternatives. This new version, although less ambitious than the old version, has sufficient force to show that presently accepted theories will be overturned, and yet does not make an (illegitimate) inference to infinity. So it stands while the argument from neighboring theories falls.

On close examination, however, the new version of the PUA does not have enough power to show that current theories will be rejected. Of course, it is possible that scientists have not yet discarded enough false theories before they reach true theories, and that consequently, current theories will be discarded. It is, however, also possible that scientists have already discarded enough false theories before they reach true theories, and that 
consequently, current theories will not be discarded. As Samuel Ruhmkorff observes, "as long as there is a finite number of theories in a domain, the falsity of past theories will tend to increase rather than decrease our confidence in current theory" (Ruhmkorff, 2013: 412).

Suppose that five alternatives exist in the possibility space of theories of disease. In this case, the germ theory is false, and scientists need to oust more false theories before they reach the true theory of disease. Suppose, however, that there are only three theories in the possibility space. In this case, the germ theory is true, and scientists have already reached the true theory. The mere historical fact that scientists have eliminated the two theories of disease does not give us any clue as to which probability is higher. So pessimists have the burden of showing that "the probability that scientists have not yet eliminated enough false alternatives is higher than the probability that scientists have eliminated enough false alternatives" (Park, 2019: Section 3.1). No pessimist, however, has yet provided an argument to show that the former probability is higher than the latter probability.

It is for this reason that pessimists should claim that infinitely many alternatives exist. If infinitely many alternatives exist, pessimists do not have the burden of showing that it is more likely that scientists have not yet ousted enough false theories, for scientists will never be able to eliminate enough false alternatives. To contend, however, that infinitely many alternatives exist is to open the door to the argument from neighboring theories.

My foregoing response to Stanford's inference to an infinite number of alternatives differs from that of Ruhmkorff (2013). Ruhmkorff claims that there "may be chunks of possibility space that are very implausible" (2013: 412). The possible existence of such chunks opens the possibility that "only 10 of the infinitely many unconceived alternatives are plausible while the others are widely implausible" (Ruhmkorff, 2013: 412).

However, it is not enough to merely point out that only ten of them might be plausible. After all, this possibility is cancelled out by the opposite possibility that ten of them are implausible and the rest of them are plausible. Moreover, Ruhmkorff's position contrasts with Stanford's position. Ruhmkorff does not attempt to support his position, whereas Stanford does, i.e., he provides the list of past theories cited in Section 2.

\subsection{Why Stronger?}

Pessimists might argue that when we consider whether we should believe in evolutionary theory, we should weigh the PUA against the argument from neighboring theories. The former claims that there are infinitely many alternatives to evolutionary theory, while the latter claims that there are infinitely many neighboring theories that cohere with evolutionary theory. What is the reason for thinking that the argument from neighboring theories is stronger than the PUA?

The reason can be found in the comparison between Stanford's list in Section 2 and the list of neighboring theories in Section 3. According to Stanford's list, there were three theories of evolution: Cuvier's theory, Lamarck's autogenesis, and Darwin's evolutionary theory. According to the list of neighboring theories, however, evolutionary theory directly coheres with five neighboring theories. Moreover, the neighboring theories are more successful than Cuvier's theory and Lamarck's theory, given that "present theories are more successful than past theories" (Park, 2018d: 8). This observation has already been made by many writers (Musgrave, 1985; Leplin, 1997; Doppelt, 2007; Doppelt, 2011; Saatsi, 2009; Devitt, 2011; Fahrbach, 2011a; Fahrbach, 2011b; Park, 2011b; Mizrahi, 2013; Doppelt, 2014). It follows that the inductive force of the argument from neighboring theories is greater than that of the PUA.

Similar arguments can be constructed in favor of the neighboring theories of evolutionary theory. For example, the germ theory has two predecessors: the humoral and 
miasma theories. But it directly and/or indirectly coheres with its neighboring theories, such as evolutionary theory, electromagnetic theory, molecular biology, and the theory of plate tectonics. Moreover, its neighboring theories are more successful than its predecessors. Thus, the germ theory is more likely to be reinforced by its neighboring theories than to be overthrown by an alternative.

\subsection{Huntington's Disease}

Critics might object that the example of Huntington's disease differs from the other examples. ${ }^{2}$ In the example of Huntington's disease, the explanation proffered only answers an explanatory question for evolutionary theory. This kind of explanation seems different from the others in that it merely answers an objection to evolutionary theory and does not explain new phenomena in conjunction with its neighboring theory.

In my view, there is no relevant difference between the example of Huntington's disease and the other examples, such as the example of skin pigmentations. Evolutionary theory was not originally designed to explain the way in which people of different pigmentations are distributed around the world. It, however, explains the phenomenon in cooperation with electromagnetic theory. Similarly, evolutionary theory was not originally designed to explain why some people suffer from Huntington's disease. Evolutionary theory explains the phenomenon in conjunction with molecular biology. In both cases, the existence of an explanandum is a new challenge to evolutionary theory, and evolutionary theory meets the new challenge with the help of its neighboring theories.

\subsection{Finitely Many Theories Again}

I argued in Section 4 that there are infinitely many neighboring theories. Pessimists might object that it is not necessary for realists to appeal to infinitely many neighboring theories. ${ }^{3}$ Realists only need finitely many neighboring theories. Evolutionary theory is warranted if it coheres with, say, 500,000 neighboring theories. Similarly, pessimists only need finitely many alternatives. A present theory is unwarranted if there are, say, 500,000 alternatives to it.

Retreating to finitely many theories comes with costs for both realists and pessimists. If realists say that there are finitely many neighboring theories, they should give up the previous claim that the probability of evolutionary theory is fated to go above $99 \%$. If pessimists say that there are finitely many successive alternatives, they should show that scientists have not yet ousted enough false theories.

Moreover, the PUA is built upon the assumption that the "more theories were replaced by unconceived alternatives, the more likely it is that present theories will be superseded by unconceived alternatives" (Park, 2016: 838). It implies that the more that accepted theories are replaced by alternatives, the greater the inductive rationale becomes for concluding that such alternatives exist. Suppose that we have 500 discarded theories, and that our scientific offspring will have 500,000 discarded theories. Obviously, our scientific offspring's inductive rationale is stronger than our inductive rationale. Thus, the inductive rationale for the existence of alternatives will only grow stronger, and we have no choice but to conclude that infinitely many alternatives exist. By parity of reasoning, I suggest, the inductive rationale for the existence of neighboring theories will only grow stronger. Thus, we have no choice but to conclude that infinitely many neighboring theories exist.

\footnotetext{
${ }^{2}$ I thank the first referee for this objection.

${ }^{3}$ I thank the first referee for this objection.
} 


\subsection{The Conflict with Neighboring Theories}

Objectors might say that I have not adequately supported the contention that there are infinitely many neighboring theories to cohere with evolutionary theory. ${ }^{4}$ From the fact that several once unconceived theories were eventually conceived and then supported evolutionary theory, it does not follow that the majority of currently unconceived ones will also be conceived and support evolutionary theory. It might be that they will rather conflict with evolutionary theory.

There should, however, be an inductive rationale for thinking so. It is not enough to merely point out that the majority of unconceived neighboring theories might conflict with evolutionary theory. After all, this possibility is cancelled out by the opposite possibility that the majority of unconceived neighboring theories cohere with evolutionary theory. Moreover, the objectors' position contrasts with my position. I have the list of the four neighboring theories that I claim support my position, whereas the objectors do not have a list of neighboring theories that would support their position. The prospect of such a list is dim, as I have already argued in Section 3.

\subsection{General Relativity and Quantum Mechanics}

Objectors might now say that this paper overlooks the case of inconsistency between general relativity and quantum mechanics. ${ }^{5}$ The inconsistency between these two fundamental physical theories makes scientific realism untenable.

I already preempted such an objection in Section 3. Recall that the argument from neighboring theories for evolutionary theory is intended to justify evolutionary theory but not other scientific theories. So if scientific antirealists want to refute the argument from neighboring theories for evolutionary theory, they should provide a list of neighboring theories that clash with evolutionary theory. It is a red herring to talk about the inconsistency between general relativity and quantum mechanics in the context of talking about evolutionary theory. Evolutionary theory claims, for example, that all current species on Earth have evolved from a common ancestor. The epistemic status of this claim is independent of the issue of whether spacetime is continuous or granular. It is a fallacious inference that since we do not know whether spacetime is continuous or granular, we do not know whether all current species on Earth have evolved from a common ancestor. Furthermore, it is not clear how much threat the inconsistency between the two physical theories poses to scientific realism, as Park (2015: 223, 2018b: Section 5) argues.

\subsection{Individuating Theories}

Finally, pessimists might object that it is not clear how we can individuate theories, i.e., what criteria can be deployed to draw the boundaries between theories. For example, it is not clear what entitles us to say that evolutionary theory and molecular biology are different theories. It follows that it is not clear how many neighboring theories evolutionary theory directly coheres with, although I claimed in Section 3 that it coheres with four neighboring theories, including molecular biology.

This objection is reasonable and should be addressed by all participants in the scientific realism debate, including pessimists. Larry Laudan, for example, contends that "for every

\footnotetext{
${ }^{4}$ I thank the second referee for this objection.

${ }^{5}$ I thank the second referee for this objection.
} 
highly successful theory in the past of science which we now believe to be a genuinely referring theory, one could find half a dozen once successful theories which we now regard as substantially non-referring" (1981: 35). Such a gloomy portrayal of past science is necessary for the pessimistic induction to get off the ground. The gloomy portrayal, however, presupposes that there are criteria for individuating past theories. Unfortunately, no philosopher has yet provided such criteria. So we have an interesting problem that every participant in the realism debate should address.

\section{Conclusion}

The argument from neighboring theories holds that since evolutionary theory coheres with its several neighboring theories, it will cohere with infinitely many neighboring theories. This argument for evolutionary theory is different from the no-miracles argument for evolutionary theory, which says that the truth of it best explains its success. In addition, the argument from neighboring theories reflects the PUA, but it is stronger than the PUA. Let me sum up this paper in a simple slogan: Neighboring theories are realists' friends.

\section{References}

Chakravartty, Anjan (2008). "What You Don't Know can't Hurt You: Realism and the Unconceived", Philosophical Studies 137 (1): 149-158.

Datta-Roy, Aniruddha and K. Praveen Karanth (2009). "The Out-Of India Hypothesis: What do Molecules Suggest?” Journal of Biociences 34 (5): 687-697.

Devitt, Michael (2011). "Are Unconceived Alternatives a Problem for Scientific Realism?", Journal for General Philosophy of Science 42 (2): 285-293.

Doppelt, Gerald (2007). "Reconstructing Scientific Realism to Rebut the Pessimistic Metainduction", Philosophy of Science 74 (1): 96-118.

(2011). "From Standard Scientific Realism and Structural Realism to Best Current

Theory Realism", Journal for General Philosophy of Science 42 (2): 295-316.

(2014). "Best Theory Scientific Realism", European Journal for Philosophy of Science 4 (2): 271-291.

Enfield, Patrick (2008). Review of P. Kyle Stanford's Exceeding Our Grasp: Science, History, and the Problem of Unconceived Alternatives, The British Journal for the Philosophy of Science 59 (4): 881-895.

Fahrbach, Ludwig (2011a). "How the Growth of Science Ends Theory Change", Synthese 180 (2): 139-155. $1283-1292$.

(2011b). "Theory Change and Degrees of Success", Philosophy of Science 78 (5):

Friedman, Michael (1981). "Theoretical Explanation", In Richard Healey, (ed.), Reduction, Time, and Reality: Studies in the Philosophy of Natural Science. Cambridge: Cambridge University Press. 
Godfrey-Smith, Peter (2008). "Recurrent Transient Underdetermination and the Glass Half Full”, Philosophical Studies 137: 141-148.

Harker, David (2008). "P. Kyle Stanford, Exceeding Our Grasp: Science, History, and the Problem of Unconceived Alternatives", Philosophy of Science 75 (2): 251-253.

Hempel, Carl (1966). Philosophy of Natural Science. Englewood Cliffs, NJ: Prentice-Hall, Inc.

Jablonski, Nina and George Chaplin (2010). "Human Skin Pigmentation as an Adaptation to UV Radiation", Proceedings of the National Academy of Sciences 107, Suppl. 2: 9862-8968.

Kitcher, Philip (1993). The Advancement of Science: Science without Legend, Objectivity without Illusion. New York: Oxford University Press.

Kowalski, Wladyslaw (2009). Ultraviolet Germicidal Irradiation Handbook: UVGI for Air and Surface Disinfection. Springer-Verlag Berlin Heidelberg. DOI 10.1007/978-3-64201999-9.

Kuhn, Thomas (1962/1970). The Structure of Scientific Revolutions. $2^{\text {nd }}$ ed. The University of Chicago Press.

Kumazawa, Yoshinori and Mutsumi Nishida (2000). "Molecular Phylogeny of Osteoglossoids: A New Model for Gondwanian Origin and Plate Tectonic Transportation of the Asian Arowana", Molecular Biology and Evolution 17 (12): 1869-1878.

Laudan, Larry (1981). “A Confutation of Convergent Realism”, Philosophy of Science 48 (1): $19-49$.

Leplin, Jarrett (1997). A Novel Defense of Scientific Realism. New York: Oxford University Press.

Mizrahi, Moti (2013). “The Pessimistic Induction: A Bad Argument Gone Too Far”, Synthese 190 (15): 3209-3226.

Musgrave, Alan (1985). "Realism vs. Constructive Empiricism”, In Paul M. Churchland \& Clifford A. Hooker (eds.), Images of Science: Essays on Realism and Empiricism. Chicago: The University of Chicago Press.

Park, Seungbae (2011a). "Coherence of Our Best Scientific Theories", Foundations of Science 16 (1): 21-30.

(2011b). "A Confutation of the Pessimistic Induction", Journal for General Philosophy of Science 42 (1): 75-84.

$218-227$.

(2015). “Accepting Our Best Scientific Theories", Filosofija. Sociologija 26 (3):

(2016). "Refutations of the Two Pessimistic Inductions", Philosophia 44 (3): 835- 
844.

(2017a). "Why Should We Be Pessimistic about Antirealists and Pessimists?" Foundations of Science. 22 (3): 613-625.

(2017b). "Selective Realism vs. Individual Realism for Scientific Creativity", Creativity Studies 10 (1): 97-107.

--------- (2017c). “On Treating Past and Present Scientific Theories Differently", Kriterion 31 (1): 63-75.

(2018a). "Justifying the Special Theory of Relativity with Unconceived Methods", Axiomathes 28 (1): 53-62.

(2018b). “Optimistic Realism over Selectivism”, Kriterion: Journal of Philosophy. (to be assigned)

--------- (2018c). “The Anti-Induction for Scientific Realism”, Grazer Philosophische Studien 95 (3): 329-342.

17: 7-19.

(2018d). “The Grand Pessimistic Induction", Review of Contemporary Philosophy

(2019). "New Objections to the Problem of Unconceived Alternatives", Filosofia Unisinos 20 (2): (to be assigned).

Psillos, Stathis (1999). Scientific Realism: How Science Tracks Truth. New York: Routledge.

370 .

(2009). "Grasping at Realist Straws", Review Symposium, Metascience 18: 363-

(2018). "Tolstoy's Argument: Realism and the History of Science", Spontaneous Generations: A Journal for the History and Philosophy of Science 9(1): 68-76.

Putnam, Hilary (1975). Mathematics, Matter and Method (Philosophical Papers, vo. 1), Cambridge: Cambridge University Press.

Ruhmkorff, Samuel (2011). "Some Difficulties for the Problem of Unconceived Alternative", Philosophy of Science 78 (5): 875-886.

(2013). "Global and Local Pessimistic Meta-inductions", International Studies in the Philosophy of Science 27 (4): 409-428.

Saatsi, Juha (2009). "Grasping at Realist Straws", Review Symposium, Metascience 18: 355362.

Soucy, Shannon, Jinling Huang \& Johann Gogarten (2015). "Horizontal Gene Transfer: Building the Web of life", Nature Reviews Genetics 16: 472-482. 
Stanford, P. Kyle (2006). Exceeding Our Grasp: Science, History, and the Problem of Unconceived Alternatives. Oxford: Oxford University Press.

(2018). “A Fond Farewell to 'Approximate Truth'?”, Spontaneous Generations: A Journal for the History and Philosophy of Science 9 (1): 78-91.

The Huntington's Disease Collaborative Research Group (1993). “A Novel Gene Containing a Trinucleotide Repeat That is Expanded and Unstable on Huntington's Disease Chromosomes", Cell 72: 971-983.

Trefil, James and Robert M. Hazen (1998). The Sciences: An Integrated Approach. New York: John Wiley \& Sons.

Vickers, Peter (2017). "Understanding the Selective Realist Defence against the PMI", Synthese 194 (9): 3221-3232.

Woodburne, Michael and William Zinsmeister (1982). "Fossil Land Mammal from Antarctica", Science 218: 284-286.

Worrall, John (1989). "Structural Realism: The Best of Both Worlds", Dialectica 43: 99-124.

Wray, K. Brad (2013). "The Pessimistic Induction and the Exponential Growth of Science Reassessed", Synthese 190 (18): 4321-4330.

(2016). "Method and Continuity in Science", Journal for General Philosophy of Science 47 (2): 363-375. 